\title{
Adubação potássica aplicada por fertirrigação e pelo método convencional na cultura do amendoim ${ }^{1}$
}

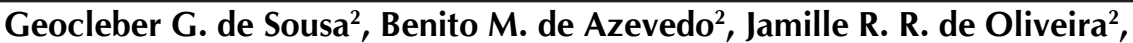 \\ Thiago de O. Mesquita ${ }^{2}$, Thales V. de A. Viana ${ }^{2} \&$ Laís M. G. do Ó ${ }^{2}$
}

\begin{abstract}
RESUMO
Com este trabalho objetivou-se avaliar doses de potássio aplicadas via fertirrigação por gotejamento e de forma convencional sobre a produtividade do amendoim. O experimento foi conduzido em campo, em Argissolo Vermelho Amarelo, em Fortaleza, Ceará. O delineamento experimental utilizado foi o de blocos ao acaso em esquema fatorial com tratamento adicional $[(3 \times 2)+1]$ e quatro repetições, sendo estudados os fatores doses de K (D1 - 25, D2 - 50 e D3 - $100 \mathrm{~kg} \mathrm{ha}^{-1}$ ) e duas formas de aplicação (F1 - Fertirrigada e F2 - Convencional) e um tratamento adicional (controle). Aos 90 dias após a semeadura foi realizada a colheita retirando-se, ao acaso, 5 plantas úteis da linha central de cada tratamento, em cada bloco. As plantas foram separadas por tratamento e acondicionadas em estufa telada por cinco dias para a secagem das vagens. As variáveis avaliadas foram: número de frutos por planta, massa de vagem, produtividade, massa de 100 sementes e tamanho de vargem. A dose de potássio aplicada de forma fertirrigada, que maximizou a produtividade $\left(1.530,68 \mathrm{~kg} \mathrm{ha}^{-1}\right)$ da cultura do amendoim foi estimada em $69,39 \mathrm{~kg} \mathrm{ha}^{-1}$ de $\mathrm{K}_{2} \mathrm{O}$ e, se aplicada pelo método convencional, em $65,80 \mathrm{~kg}$ de $\mathrm{K}_{2} \mathrm{O}$, proporcionaria uma produtividade máxima estimada em 1.092,22 kg ha-1.
\end{abstract}

Palavras-chave: Arachis ypogea L., quimigação, oleaginosa

\section{Potassium fertilization applied by fertigation and conventionally in peanut crop}

\begin{abstract}
The objective of this study was to evaluate the influence of potassium doses on peanut yield, when applied by drip fertigation or conventionally. The experiment was conducted in the field, in an Alfissol in Fortaleza, Ceará. The experimental design consisted of randomized blocks in a factorial arrangement plus one additional treatment $[(3 \times 2)+1]$ and four replications, being studied three K doses (D1 - 25, D2 - 50 and D3 $100 \mathrm{~kg} \mathrm{ha}^{-1}$ ) and two application methods (F1 - Fertigation, F2 - Conventional fertilizer application), plus one additional treatment (control). At 90 days after sowing, harvesting was performed, with 5 plants being taken at random from the central line of each treatment, in each block. These plants were separated by treatment and placed in a screened greenhouse for five days, for the pods to dry. The evaluated variables were: number of fruits per plant, pod weight, yield, 100 seed weight and pod size. The fertigated potassium dose corresponding to the maximum peanut crop yield (1530.68 kg ha-1) was estimated at $69.39 \mathrm{~kg} \mathrm{ha}^{-1}$ of $\mathrm{K}_{2} \mathrm{O}$. As to the conventionally applied potassium dose that maximized yield was estimated at $65.80 \mathrm{~kg} \mathrm{ha}^{-1}$ of $\mathrm{K}_{2} \mathrm{O}$, corresponding to a maximum peanut crop yield of $1092.22 \mathrm{~kg} \mathrm{ha}^{-1}$.
\end{abstract}

Key words: Arachis ypogea L., chemigation, oleaginous 


\section{INTRODUÇÃO}

Originária do continente sul americano, a cultura do amendoim (Arachis ypogea L.) é uma planta que se reproduz quase exclusivamente por autogamia, com início da floração entre 25 e 35 dias após o plantio, persistindo até o final do ciclo. Segundo Tasso Júnior et al. (2004) desenvolve, logo após a germinação, um ramo principal que se origina da gema apical do epicótilo e dois ramos laterais originados a partir das gemas axilares aos cotilédones. Segundo esses autores, o amendoim é uma cultura de relevante importância econômica, pelo seu alto valor nutritivo; suas sementes podem ser processadas e utilizadas diretamente na alimentação humana, nas indústrias de conservas, nas confeitarias e no biodiesel.

$\mathrm{O}$ cultivo do amendoim deve ser feito em solos que não apresentem restrições físicas e proporcionem equilíbrio nutricional durante o ciclo, visando maximizar sua produtividade (Nascimento et al., 2010). A adubação com fertilizantes à base de potássio seria uma alternativa para aumentar a produtividade da cultura do amendoim. Segundo Prado (2008) este nutriente é considerado essencial para o crescimento, desenvolvimento e qualidade de frutos dos vegetais. Para a cultura do amendoim, Tasso Júnior et al. (2004) informam que um suprimento inadequado de potássio pode ocasionar manchas amarelas próximo às margens dos folíolos nas folhas adultas, além de passíveis de provocar a formação de vagens com apenas uma semente. Por outro lado o excesso do potássio pode diminuir a absorção de $\mathrm{Ca}$ e $\mathrm{Mg}$ chegando a causar deficiência desses elementos (Prado, 2008; Freitas et al., 2007; Dantas Júnior et al., 2010).

O potássio pode ser aplicado pelo método convencional, que consiste em aplicar o adubo na linha de plantio diretamente no solo (fundação e cobertura) numa profundidade que varia de 5 a $10 \mathrm{~cm}$, onde se situa a maior parte do sistema radicular das plantas, ocorrendo contato do nutriente com maior volume do solo (Ernani et al., 2007; Oliveira et al., 2007).

Outra forma de se aplicar o potássio é através da técnica da fertirrigação. O emprego dessa técnica tem possibilitado a otimização do uso de fertilizantes em diferentes culturas irrigadas, tanto em aspectos relacionados à produtividade quanto à qualidade dos produtos obtidos, sendo mais notável sua adoção em culturas irrigadas por sistemas de irrigação localizada (Oliveira \& Villas Bôas, 2008). Entre os nutrientes aplicados por este método, os fertilizantes potássicos merecem especial atenção. Apesar de apresentar boa solubilidade, o $\mathrm{K}^{+}$ apresenta suscetibilidade a perdas por processos erosivos em áreas irrigadas, principalmente em solos com baixa CTC (Ernani et al., 2007; Oliveira et al., 2012).

Trabalhos através dos quais se objetivou aplicar, conjuntamente, $\mathrm{o}$ adubo potássico pelo método convencional e fertirrigado registraram que pelo método convencional a cultura do gergelim obteve uma produtividade média de $874,00 \mathrm{~kg}$ $\mathrm{ha}^{-1}$ (Mesquita, 2010) e a cultura da bananeira 3.170,00 $\mathrm{kg} \mathrm{ha}^{-1}$ (Teixeira et al., 2007). Para esses últimos autores, a adubação convencional determinou o acúmulo de $\mathrm{K}$ nas camadas superficiais do solo e na área mais próxima às plantas e que os efeitos da fertirrigação nos atributos químicos do solo foram mais eficiente que os da adubação convencional.
O objetivo deste trabalho foi avaliar doses de potássio aplicadas via fertirrigação por gotejamento e de forma convencional sobre a produtividade do amendoim.

\section{Material e Métodos}

O experimento foi conduzido na área experimental da Estação Agrometeorológica, pertencente ao Departamento de Engenharia Agrícola, da UFC, em Fortaleza, Ceará, situada nas coordenadas geográficas de $3^{\circ} 44^{\prime} 45^{\prime}$ ' S e $38^{\circ} 34^{\prime} 55^{\prime \prime} \mathrm{W}$ e com 19,5 $\mathrm{m}$ acima do nível médio do mar. O solo utilizado no experimento é classificado como Argissolo Vermelho Amarelo (EMBRAPA, 2006). Algumas características físicas e químicas do solo antes do experimento são apresentadas na Tabela 1 .

Tabela 1. Alguns atributos físicos e químicos do solo da área experimental, na camada de 0 a 0,2 m, antes da aplicação dos tratamentos

\begin{tabular}{lc}
\hline \multicolumn{1}{c}{ Características } & Profundidade $\mathbf{( 0 - 2 0} \mathbf{~ c m})$ \\
Classe textural & Areia franca \\
Densidade do solo $\left(\mathrm{kg} \mathrm{dm}^{-3}\right)$ & 1,54 \\
$\mathrm{Ca}\left(\mathrm{cmol}_{\mathrm{c}} \mathrm{dm}^{-3}\right)$ & 1,7 \\
$\mathrm{Mg}\left(\mathrm{cmol}_{\mathrm{c}} \mathrm{dm}^{-3}\right)$ & 1,7 \\
$\mathrm{~K}\left(\mathrm{cmol}_{\mathrm{c}} \mathrm{dm}^{-3}\right)$ & 0,09 \\
$\mathrm{P}\left(\mathrm{mg} \mathrm{dm}^{-3}\right)$ & 12 \\
$\mathrm{Na}\left(\mathrm{cmol}_{\mathrm{c}} \mathrm{dm}^{-3}\right)$ & 0,08 \\
$\mathrm{H}+\mathrm{Al}_{\left(\mathrm{cmol}_{\mathrm{c}} \mathrm{dm}^{-3}\right)}$ & 0,83 \\
$\mathrm{Al}\left(\mathrm{cmol}_{\mathrm{c}} \mathrm{dm}^{-3}\right)$ & 0,4 \\
$\mathrm{CTC}$ & 4,72 \\
$\mathrm{~V}$ & 82 \\
$\mathrm{pH}$ & 6,6 \\
\hline
\end{tabular}

O clima da região é do tipo Aw', caracterizado como tropical chuvoso, muito quente, com chuvas predominantes nas estações do verão e outono. Na Tabela 2 se encontram os dados climáticos coletados durante o experimento.

Tabela 2. Dados climáticos observados durante a condução do experimento

\begin{tabular}{llccc}
\hline \multicolumn{1}{c}{ Mês } & $\begin{array}{c}\text { Tar } \\
\left({ }^{\mathbf{0}} \mathbf{C}\right)\end{array}$ & $\begin{array}{c}\text { UR } \\
\mathbf{( \% )}\end{array}$ & $\begin{array}{c}\text { VV } \\
\left(\mathbf{m ~ s}^{-1}\right)\end{array}$ & $\begin{array}{c}\text { PREP } \\
(\mathbf{m m})\end{array}$ \\
Setembro & 28,4 & 62 & 4,2 & 0 \\
Outubro & 28,7 & 66 & 3,6 & 0 \\
Novembro & 28,9 & 65 & 4,0 & 3,4 \\
Dezembro & 28,7 & 71 & 3,5 & 60,9 \\
\hline
\end{tabular}

Tar - Temperatura do ar; UR - Umidade relativa, VV - Velocidade do vento, PREP - Precipitação Fonte: Estação Agrometeorológica do Departamento de Engenharia Agrícola do CCA/UFC

A cultura do amendoim foi semeada manualmente em 21 de setembro de 2010, com espaçamento entre linhas de 1,0 $\mathrm{m}$, em covas abertas, com uma média de quatro sementes por cova, espaçadas $0,20 \mathrm{~m}$ na linha. No $6^{\circ}$ dia após a semeadura observou-se uma germinação de $100 \%$. No desbaste, realizado manualmente, as plantas foram arrancadas rente ao solo deixando-se apenas uma planta por cova. Durante o ciclo da cultura foram realizadas duas capinas com o intuito de eliminar as ervas daninha. Foram procedidos, também, os tratamentos fitossanitários necessários, ao surgirem os primeiros sintomas de pragas e doenças.

As irrigações foram realizadas por gotejamento, durante todo o ciclo da cultura, usando-se um gotejador autocompensante 
para cada planta. A vazão média dos emissores era de $2,0 \mathrm{~L} \mathrm{~h}^{-1}$ e pressão de serviço de $1,0 \mathrm{kgf} \mathrm{cm} \mathrm{cm}^{-2}$.

O delineamento experimental utilizado foi o de blocos ao acaso em um esquema fatorial com tratamento adicional [ $(3 \mathrm{x}$ $2)+1$ ] e quatro repetições, sendo estudados os fatores doses de $\mathrm{K}\left(\mathrm{D} 1=25, \mathrm{D} 2=50\right.$ e D3 $\left.=100 \mathrm{~kg} \mathrm{ha}^{-1}\right)$ e duas formas de aplicação $(\mathrm{F} 1=$ fertirrigada e $\mathrm{F} 2=$ convencional $)$ e um tratamento adicional (controle).

A adubação das plantas do amendoim foi baseada na análise de solo da área experimental e consistiu, basicamente, na aplicação de 13,33 g de ureia, 294,11 g de superfosfato simples e $80 \mathrm{~g}$ de cloreto de potássio por cova, correspondente às doses de $15,62,5$ e $50 \mathrm{~kg} \mathrm{ha}^{-1}$ de $\mathrm{N}, \mathrm{P}_{2} \mathrm{O}_{5}$ e $\mathrm{K}_{2} \mathrm{O}$, respectivamente, de acordo com Fernandes (1993) aplicadas de forma convencional e fertirrigada.

$\mathrm{Na}$ forma convencional os adubos foram aplicados de uma vez em fundação, em que os adubos foram fornecidos às plantas em sulcos abertos paralelamente às linhas laterais. Em fundação foram aplicados toda a dose de $\mathrm{N}\left(15 \mathrm{~kg} \mathrm{ha}^{-1} \mathrm{de}\right.$ ureia) e de $\mathrm{P}\left(62,5 \mathrm{~kg} \mathrm{ha}^{-1}\right.$ de superfosfato simples), metade da dose recomendada para o $\mathrm{KCl}$ ( $25 \mathrm{~kg} \mathrm{ha}^{-1}$ para o T2), a dose recomendada para o $\mathrm{KCl}\left(50 \mathrm{~kg} \mathrm{ha}^{-1}\right.$ para o T4) e o dobro da dose recomendada para o $\mathrm{KCl}\left(100 \mathrm{~kg} \mathrm{ha}^{-1}\right.$ para o T6); já na fertirrigação as doses foram parceladas em oito aplicações realizadas semanalmente, a primeira aplicada aos 8 DAS.

Aos 90 dias após a semeadura foi realizada a colheita, que consistiu no corte da planta inteira, no nível do solo, sendo retiradas, ao acaso, cinco plantas úteis da linha central de cada tratamento, em cada bloco. As plantas foram separadas por tratamento e acondicionadas em estufa telada por cinco dias para a secagem das vagens. As variáveis agronômicas avaliadas nesse estudo foram: número de frutos por planta, massa de vagem, produtividade, massa de 100 sementes e tamanho de vargem.

Os resultados obtidos foram submetidos a análises de variância e de regressão e, de acordo com o nível de significância, ao teste $\mathrm{F}$ para as doses e forma de aplicação, procedeu-se à analise de regressão polinomial utilizando-se o nível de 0,01 ou 0,05 de probabilidade sendo apresentados os modelos polinomiais de melhor ajuste. No programa computacional utilizando-se o SAEG/UFV.

\section{Resultados E Discussão}

Na Tabela 3 estão dispostos os valores da análise de variância para o número de vagem por planta (NVP), a massa de vagem (MV), a massa de 100 sementes (M100S), o comprimento de vagem (COV) e a produtividade (PROD) da cultura do amendoim em função das doses de adubação potássica pelos métodos convencional e fertirrigado. As diferentes doses de potássio $\left(25,50 \mathrm{e} 100 \mathrm{~kg} \mathrm{ha}^{-1}\right)$ influenciaram significativamente em nível de 5\% pelo teste F o NVP, a MV e a PROD, enquanto para as formas de aplicação (fertirrigada e convencional) houve efeito significativo em nível de 0,01 e 0,05 pelo teste $F$ para o NVP e o MV.

$\mathrm{O}$ efeito não significativo das variáveis M100S e COV se deve ao fato do amendoinzeiro poder diversificar o deslocamento de nutriente via floema em relação à aplicação direta de
Tabela 3. Resumo da análise de variância para o número de vagem por planta (NVP), massa de vagem (PV), produtividade (PROD), massa de 100 sementes (P100S) e tamanho de vagem (TV), sob diferentes doses de $\mathrm{K}_{2} \mathrm{O}$ aplicadas de forma fertirrigada e convencional, aos 90 DAS

\begin{tabular}{|c|c|c|c|c|c|}
\hline \multirow{2}{*}{ FV } & \multicolumn{4}{|c|}{ Quadrado médio } & \multirow{2}{*}{ PROD } \\
\hline & NVP & MV & COV & M100S & \\
\hline Doses (D) & $861,31^{\star \star}$ & $1,88^{\star \star}$ & $0,21^{\text {ns }}$ & $31,83^{\text {ns }}$ & $346917,86^{\star \star}$ \\
\hline Formas $(F)$ & $1513,68^{\star \star *}$ & $3,91^{\star}$ & $2,22^{\text {ns }}$ & $5,81^{\mathrm{ns}}$ & $126905,12^{\mathrm{ns}}$ \\
\hline Interação D x F & $289,45^{\star \star *}$ & $0,88^{\star}$ & $4,60^{\text {ns }}$ & $24,07^{\text {ns }}$ & $1294918,1^{* *}$ \\
\hline Fatorial x T & $18,53^{\star \star}$ & $4,39 *$ & $7,45^{\star \star}$ & $411,5^{\star \star}$ & $689767,37^{\star \star}$ \\
\hline Tratamentos & $638,95^{\star *}$ & $2,54^{\star}$ & $3,22^{\star}$ & $6,93^{\star *}$ & $683390,73^{\star \star}$ \\
\hline Resíduo & 27,09 & 0,72 & 0,1 & 12,71 & 38762,46 \\
\hline \multicolumn{6}{|l|}{ Total } \\
\hline CV (\%) & 11,28 & 23,16 & 3,10 & 8,84 & 21,40 \\
\hline Média Geral & 46,14 & 3,67 & 3,47 & 40,33 & 919,58 \\
\hline
\end{tabular}

FV - Fonte de variação; GL - Grau de liberdade; CV - Coeficiente de variação; T - Testemunha;

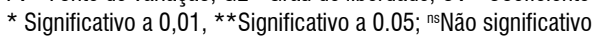

fertilizantes (Tasso Júnior et al., 2004). Outro aspecto que pode ter influenciado as respostas isoladas das doses de $\mathrm{K}_{2} \mathrm{O}$ sobre o desempenho produtivo da cultura do amendoim pode estar na eficiência de absorção da planta ou redução da lixiviação (Prado, 2008; Miranda et al., 2010). Os resultados obtidos nesta pesquisa são similares aos verificados para os cultivares IAC-8112, CNPA BR-1 e PI-165317, cultivados em campo, em Paraipaba, CE, por Souza (2007) em plantio convencional. Miranda et al. (2010) concluíram, estudando plantas de amendoim em lisímetro de pesagem sob telado, que a cultura não apresentou deficiência nutricional de $\mathrm{K}$ até os 55 DAS.

A interação significativa e a análise comparativa das médias através do teste Tukey, das diferentes doses de $\mathrm{K}_{2} \mathrm{O}$ dentro de cada método de aplicação para as variáveis: número de vagem por planta, massa de vagem e produtividade não significativas para o peso de 100 sementes e o comprimento de vagem, podem ser vistas na Tabela 4.

Tabela 4. Valores médios das interações significativas da análise de variância referentes ao número de vagem por planta, massa de vagem e produtividade sob diferentes doses de $\mathrm{K}_{2} \mathrm{O}$ aplicadas de forma fertirrigada (FERT) e convencional (CONV), aos 90 DAS

\begin{tabular}{|c|c|c|}
\hline \multirow{2}{*}{$\begin{array}{c}\text { Doses de K } \\
\left(\mathrm{kg} \mathrm{ha}^{-1}\right)\end{array}$} & \multicolumn{2}{|c|}{ Métodos de aplicações } \\
\hline & FERT & CONV \\
\hline & \multicolumn{2}{|c|}{ Número de vagem } \\
\hline 25 & $42,5 \mathrm{a}$ & $38,55 \mathrm{~b}$ \\
\hline 50 & $71,5 \mathrm{a}$ & $42,55 b$ \\
\hline \multirow[t]{3}{*}{100} & $48,8 \mathrm{a}$ & $48,15 \mathrm{a}$ \\
\hline & \multicolumn{2}{|c|}{ DMS Método = 7,65 } \\
\hline & \multicolumn{2}{|c|}{ Massa de vagem $(\mathrm{g})$} \\
\hline 25 & $3,28 \mathrm{a}$ & $2,78 \mathrm{~b}$ \\
\hline 50 & $4,29 \mathrm{a}$ & $4,48 \mathrm{a}$ \\
\hline \multirow[t]{3}{*}{100} & $3,55 \mathrm{a}$ & $3,01 \mathrm{~b}$ \\
\hline & \multicolumn{2}{|c|}{ DMS Método $=0,83$} \\
\hline & \multicolumn{2}{|c|}{ Produtividade $\mathrm{kg} \mathrm{ha}^{-1}$} \\
\hline 25 & $748,77 b$ & $688,57 \mathrm{~b}$ \\
\hline 50 & $1685,45 \mathrm{a}$ & $1180,00 \mathrm{~b}$ \\
\hline \multirow[t]{2}{*}{100} & $1265,45 \mathrm{a}$ & $900,60 \mathrm{~b}$ \\
\hline & \multicolumn{2}{|c|}{ DMS Método $=351,01$} \\
\hline
\end{tabular}

Médias seguidas da mesma letra na coluna não diferem estatisticamente entre si (Tukey 0,05), DMS - diferença mínima significativa 
Ao se comparar apenas os métodos de aplicação de potássio observa-se, para o NVP e o MV, que apenas a metade da dose recomendada $\left(25 \mathrm{~kg} \mathrm{ha}^{-1}\right)$ aplicada pelo método convencional apresentou superioridade em relação ao método fertirrigado. Para produtividade, o método fertirrigado foi superior apenas no dobro da dose recomendada $\left(200 \mathrm{~kg} \mathrm{ha}^{-1}\right)$ em relação ao método convencional.

Tasso Júnior et al. (2004) reforçam que, apesar da cultura do amendoim não ser muito exigente em nutrientes, o potássio aumenta, quando aplicado de forma correta, a qualidade e a quantidade de vagens.

De acordo com a análise de regressão apresentada na Figura 1 , as plantas adubadas pelo método fertirrigado apresentaram maior número de vagens por planta quando comparadas com as adubadas pelo método convencional. No que diz respeito a essa variável, quando se utilizou apenas o método fertirrigado, verificou-se que o modelo quadrático foi o que obteve melhor ajuste com coeficiente de determinação de 0,81 . Por este modelo as plantas produziriam um número máximo de vagens por planta (64) com a dose estimada em $68 \mathrm{~kg} \mathrm{ha}^{-1}$ de $\mathrm{K}_{2} \mathrm{O}$.

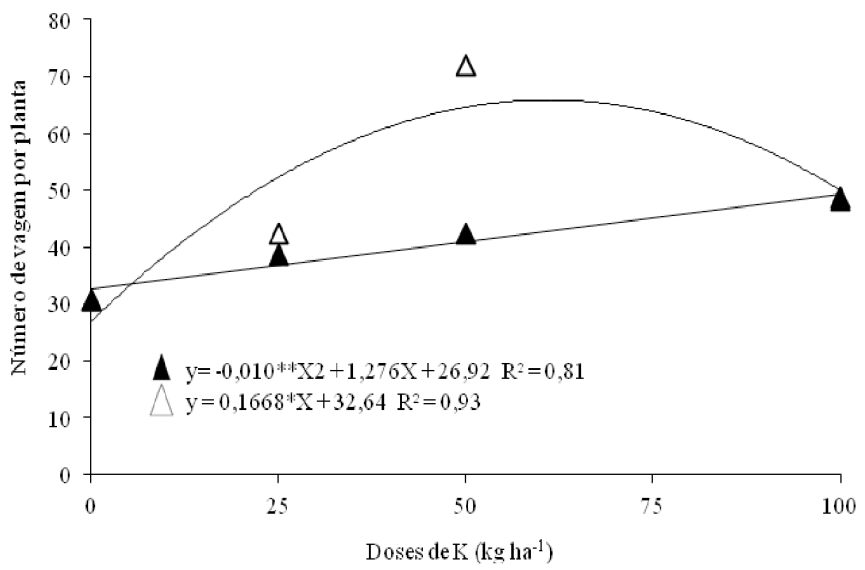

Figura 1. Número de vagens por planta de amendoinzeiro em função de doses de potássio aplicadas pelo método convencional $(\triangle)$ e fertirrigado $(\boldsymbol{\Lambda})$

Na mesma área experimental Mesquita (2010) evidenciou, avaliando fertirrigação potássica na cultura do gergelim, tendências semelhantes às deste estudo; entretanto, com tomate em casa de vegetação Macêdo \& Alvarenga (2005) verificaram que a fertirrigação potássica não exerceu efeito significativo para esta variável.

Para a adubação potássica convencional, o modelo que melhor se ajustou foi o linear crescente, com $\mathrm{R}^{2}$ de 0,93 (Figura 1). Resultado semelhante foi observado por Souza (2007) aplicando $\mathrm{K}$ de forma convencional na mesma cultivar deste estudo, em Paraipaba, Ceará e por Mesquita (2010) que, na mesma área experimental obteve, com a cultura do gergelim, resposta significativa para o número de frutos por planta, sendo o modelo quadrático o de melhor ajuste.

A disponibilidade de $\mathrm{K}$ para as plantas depende muito de sua difusão no solo (Prado, 2008; Neves et al., 2009) uma vez que a quantidade que chega às raízes por fluxo de massa é muito menor que a taxa de absorção. $\mathrm{O}$ efeito positivo do $\mathrm{K}$ sobre o número de vagens deve estar condicionado às várias funções que este cátion exerce no metabolismo vegetal, sendo ativador de enzimas durante o processo de fotossíntese, respiração e síntese de proteínas, atuando também na abertura estomática, no transporte via floema, na osmorregulação e na extensão celular (Prado, 2008; Melo et al., 2010).

A massa de vagem do amendoinzeiro em função das doses de potássio aplicadas pelo método fertirrigado, ajustou-se ao modelo polinomial quadrático, $\mathrm{R}^{2}$ de 0,98 , apresentando maior peso de vagem que o método convencional (Figura 2). A dose de potássio que proporcionou a maximização da massa de vagem da cultura do amendoim aos 90 DAS $(4,18 \mathrm{~g})$ foi estimada em 62 $\mathrm{kg} \mathrm{ha}^{-1}$ de $\mathrm{K}_{2} \mathrm{O}$. Essa situação revela que, para a referida variável, a cultura utilizou maior quantidade que a recomendada. Tal resultado pode ter ocorrido em função de um estímulo maior ao desenvolvimento do sistema radicular, formação dos primórdios das partes reprodutivas e das vagens (Tasso Júnior et al., 2004), proporcionado pela distribuição das doses crescentes de potássio aplicado via água de irrigação (Donagemma et al., 2008). Reforçando esta informação, Laurindo et al. (2010) concluíram que os teores de $\mathrm{K}$ aplicado no solo por fertirrigação diminuem radialmente com o aumento da distância horizontal do ponto de aplicação pelo gotejador, na direção ortogonal à linha de plantas.

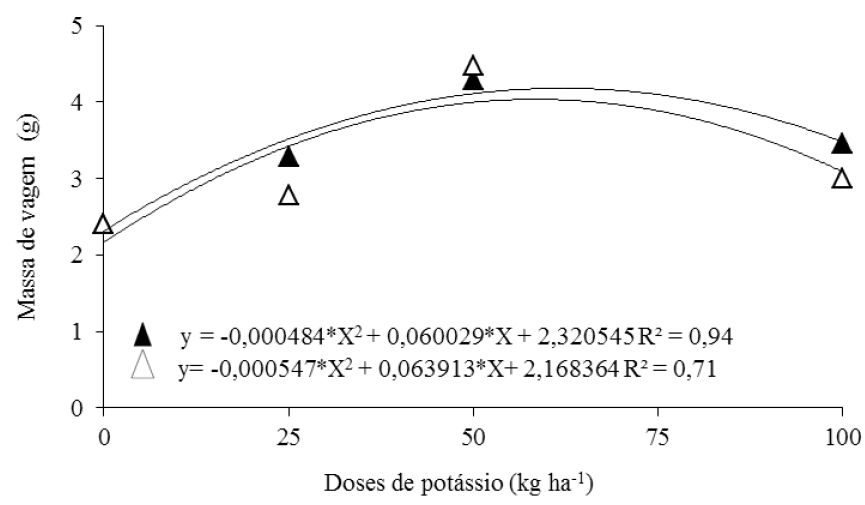

Figura 2. Massa de vagem do amendoinzeiro em função de doses de potássio aplicadas pelo método convencional $(\triangle)$ e fertirrigado $(\boldsymbol{\Lambda})$

Trabalhos com fertirrigação potássica na cultura do amendoim ainda são escassos porém com outras culturas já vêm sendo abordados. Por exemplo, Mesquita (2010) não observou, avaliando diferentes doses fertirrigadas de $\mathrm{K}_{2} \mathrm{O}$, nas mesmas condições de solo e clima deste estudo, resultados significativos para o peso de vagens da cultura do gergelim; já Genúncio et al. (2010) cultivando tomate em ambiente protegido aplicando potássio por fertirrigação registraram efeito significativo (modelo linear) sob a massa de fruto.

As doses de potássio aplicadas pelo método convencional, também exerceram efeitos sobre a massa de vagens. Com base na Figura 2 o modelo que melhor se ajustou foi o polinomial quadrático, $\mathrm{R}^{2}$ de 0,71 . A estimativa para o peso máximo de vagem $(4,04)$ foi obtida com a dose de 58,43 de $\mathrm{kg} \mathrm{ha}^{-1}$ de $\mathrm{K}_{2} \mathrm{O}$. $\mathrm{O}$ aspecto positivo das doses de potássio sobre o peso de vagem está relacionado à boa nutrição das plantas, principalmente na época de florescimento e na penetração do ginóforo.

Souza (2007) obteve, com a mesma cultivar de amendoim, em Paraipaba, CE, respostas similares às deste estudo para o peso de vagem. Estudando a influência da aplicação de potássio de forma convencional na cultura do gergelim, em Fortaleza, 
Ceará, Mesquita (2010) não encontrou resultados significativos para esta variável. A utilização de diferentes doses de potássio aplicadas pelo método convencional tem contribuído para o aumento do peso de frutos de outras culturas como a mamoneira (Severino et al., 2006) e girassol (Uchôa et al., 2011).

Ao analisar o efeito das diferentes doses de potássio sobre a produtividade do amendoinzeiro, pela análise de regressão (Figura 3) o modelo polinomial quadrático foi o que melhor se ajustou aos dados, tanto para o método fertirrigado como para o convencional, com efeito significativo $(\mathrm{P}<0,01)$ e $\mathrm{R}^{2}$ de 0,87 e 0,79 , respectivamente.

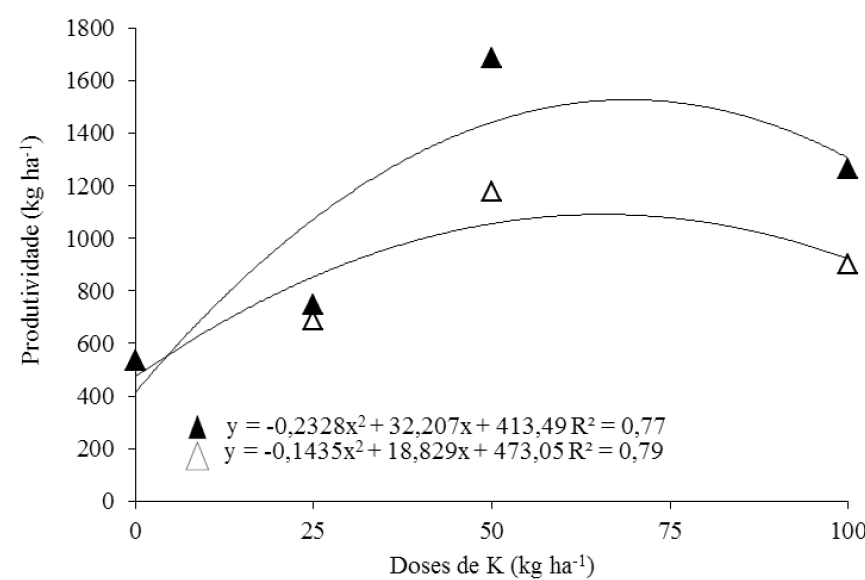

Figura 3. Produtividade da cultura do amendoim em função de doses de potássio aplicadas pelo método convencional $(\triangle)$ e fertirrigado $(\Delta)$

A produtividade máxima estimada para a cultura do amendoim com o método fertirrigado foi de $1.530,68 \mathrm{~kg} \mathrm{ha}^{-1}$ com a dose de $69,39 \mathrm{~kg} \mathrm{ha}^{-1}$ de $\mathrm{K}_{2} \mathrm{O}$ enquanto para o método convencional a produtividade máxima estimada foi de 1.092,22 $\mathrm{kg} \mathrm{ha}^{-1}$ com a dose de $65,80 \mathrm{~kg} \mathrm{ha}^{-1}$ de $\mathrm{K}_{2} \mathrm{O}$. Este resultado indica uma superioridade do método fertirrigado em relação ao convencional de $438,46 \mathrm{~kg} \mathrm{ha}^{-1}(28,64 \%)$ de grãos de amendoim. A produtividade obtida com método fertirrigado está acima da média do Ceará, $1.151,57 \mathrm{~kg} \mathrm{ha}^{-1}$ enquanto pelo método convencional ficou abaixo da média nacional, 2.225 $\mathrm{kg} \mathrm{ha}^{-1}$ (IBGE, 2011).

Mesquita (2010) encontrou, cultivando gergelim, e Nobre et al. (2010) com mamona, avaliando fertirrigação potássica para essas culturas, no mesmo local desse estudo, produtividade de 656,26 e $3.342,2 \mathrm{~kg} \mathrm{ha}^{-1}$, respectivamente. Para o método convencional, Souza (2007) obteve uma produtividade superior à deste estudo (2.800 $\left.\mathrm{kg} \mathrm{ha}^{-1}\right)$ em Paraipaba, Ceará, com a cultivar PI-165317. Crusciol \& Soratto (2007) verificaram, aplicando doses de $\mathrm{K}_{2} \mathrm{O}$ de forma convencional no amendoinzeiro, que não houve efeito significativo para a produtividade.

As produtividades de grãos obtidas neste trabalho corroboram com as obtidas por Lazarini \& Crusciol (2000) em condições de cultivo de sequeiro. Esses autores obtiveram, em época de semeadura do amendoim semelhante à adotada no presente estudo, produtividade na região de Selvíria, Mato Grosso do Sul variando entre 1.600 e $2.200 \mathrm{~kg} \mathrm{ha}^{-1}$.

Outros estudos através dos quais se obtiveram o mesmo comportamento deste estudo, foram observados por Uchôa et al. (2011) com a cultura do girassol e por Freitas et al.
(2007) com a cultura do algodão utilizando a dose recomendada de $\mathrm{K}_{2} \mathrm{O}\left(60 \mathrm{~kg}\right.$ de $\left.\mathrm{K}_{2} \mathrm{O} \mathrm{ha}^{-1}\right)$.

\section{CONClusõES}

1. A aplicação de diferentes doses de $\mathrm{K}_{2} \mathrm{O}$ de forma convencional e por fertirrigação na cultura do amendoim, não diferiu estatisticamente da testemunha para as variáveis: comprimento de vagem e massa de 100 sementes.

2. A dose de potássio aplicada de forma fertirrigada, que maximizou a produtividade $\left(1.530,68 \mathrm{~kg} \mathrm{ha}^{-1}\right)$ da cultura do amendoim, foi estimada em $69,39 \mathrm{~kg} \mathrm{ha}^{-1}$ de $\mathrm{K}_{2} \mathrm{O}$ e, se aplicada pelo método convencional, em $65,80 \mathrm{~kg}$ de $\mathrm{K}_{2} \mathrm{O}$, proporcionará uma produtividade máxima estimada de $1.092,22 \mathrm{~kg} \mathrm{ha}^{-1}$.

\section{Literatura Citada}

Crusciol, C. A. C.; Soratto, R. P. Nutrição e produtividade do amendoim em sucessão ao cultivo de plantas de cobertura no sistema plantio direto. Pesquisa Agropecuária Brasileira, v.42, p.1553-1560, 2007.

Dantas Júnior, E. E.; Chaves, L. H. G.; Costa, F. A.; Mesquita, E. F.; Araújo, D. Crescimento de duas cultivares de mamoneira adubadas com potássio, cobre e zinco. Revista Caatinga, v.23, p.97-107, 2010.

Donagemma, G. K.; Ruiz, H. A.; Alvarez V., V. H.; Ferreira, P. A.; Centarutti, R. B.; Silva, A. T.; Figueiredo, G. C. Distribuição do amônio, nitrato, potássio e fósforo em colunas de latossolos fertirrigadas. Revista Brasileira de Ciência do Solo, v.32, p.2493-2504, 2008.

EMBRAPA - Empresa Brasileira de Pesquisa Agropecuária. Sistema brasileiro de classificação de solos. 2.ed. Rio de Janeiro: Embrapa Solos, 2006. 306p.

Ernani, P. R.; Almeida, J. A.; Santos, F. C. Potássio. In: Novais, R. F.; Venegas, V. H. A.; Barros, N. F.; Fontes, R. L. F.; Cantarutti, R. B.; Neves, J. C. L. (ed.). Fertilidade do solo. Viçosa: Sociedade Brasileira de Ciência do Solo, 2007. Cap.9, p.501-589.

Fernandes, V. L. B. Recomendações de adubação e calagem para o estado do Ceará. Fortaleza: UFC, 1993. 248p.

Freitas, R. J.; Leandro, W. M.; Carvalho, M. C. S. Efeito da adubação potássica via solo e foliar sobre a produção e a qualidade da fibra em algodoeiro (Gossypium hirsutum L.). Pesquisa Agropecuária Tropical, v.37, p.106-112, 2007.

Genúncio, G. C.; Silva, R. A. C.; Sá, N. M.; Zonta, E.; Araújo, A. P. Produção de cultivares de tomateiro em hidroponia e fertirrigação sob razões de nitrogênio e potássio. Horticultura Brasileira, v.28, p.446-452, 2010.

IBGE - Instituto Brasileiro de Geografia e Estatística. Produção Agrícola. <http://www.ibge.gv.br/home/estatistica>. 23 Mar. 2011.

Laurindo, V. T.; Silva, G. O.; Pavani, L. C.; Quaggio, J. A. Padrão de distribuição de $\mathrm{K}^{+}, \mathrm{Ca}^{++}, \mathrm{Mg}^{++}$e $\mathrm{P}$ no solo de um pomar de citros em função da fertirrigação. Engenharia Agrícola, v.30, p.909-921, 2010.

Lazarini, E.; Crusciol, C. A. C. Produtividade do amendoim da seca em função do sistema de produção e da época de semeadura. Revista de Agricultura, v.75, p.287-301, 2000. 
Macêdo, L. S.; Alvarenga, M. A. R. Efeitos de lâminas de água e fertirrigação potássica sobre o crescimento, produção e qualidade do tomate em ambiente protegido. Ciência e Agrotecnologia, v.29, p.296-304, 2005.

Mesquita, J. B. R. Manejo da cultura do gergelim submetida a diferentes lâminas de irrigação, doses de nitrogênio e de potássio aplicadas pelo método convencional e por fertirrigação. Fortaleza: UFC, 2010. 82p. Dissertação Mestrado

Melo, A. S. de; Fernandes, P. O.; Sobral, L. F.; Brito, M. E. B.; Dantas, J. D. M. Crescimento, produção de biomassa e eficiência fotossintética da bananeira sob fertirrigacão com nitrogênio e potássio. Revista Ciência Agronômica, v.41, p.417-426, 2010.

Miranda, J. H.; Bérgamo, L. R.; Reis, J. B. R. S.; Cruciani, D. E.; Duarte, S. N. Distribuição da concentração de potássio no solo em lisímetros cultivados com amendoim. Engenharia Agrícola, v.30, p.253-263, 2010.

Nascimento, I. S.; Monks, P. L.; Vahl, L. C.; Coelho, R. W.; Silva, J. B.; Fischer, V. Aspectos qualitativos da forragem de amendoim forrageiro cv. Alqueire-1 sob manejo de corte e adubação PK. Revista Agrociência, v.16, p.117123, 2010.

Neves, L. S.; Ernani, P. R.; Simonete, M. A. Mobilidade de potássio em solos decorrente da adição de doses de cloreto de potássio. Revista Brasileira de Ciência do Solo, v.33, p.25-32, 2009.

Nobre, J. G. A.; Viana, T. V. A.; Moreira, L. G.; Albuquerque, A. H. P.; Azevedo, B. M.; Lima, A. D. Influência da fertirrigação potássica na produtividade da mamoneira. Revista Brasileira de Agricultura Irrigada, v.4, p.207-216, 2010.
Oliveira, A. P.; Silva, J. A.; Alves, A. U.; Dorneles, C. S. M.; Alves, A. U.; Oliveira, A. N. P. Cardoso, E. A.; Cruz, I. S. Rendimento de feijão-vagem em função de doses de $\mathrm{K}_{2} \mathrm{O}$. Horticultura Brasileira, v.25, p.29-33, 2007.

Oliveira. E. L.; Faria, M. A.; Evangelista, A. W. P.; Melo, P. C. Resposta do pinhão-manso à aplicação de níveis de irrigação e doses de adubação potássica. Revista Brasileira de Engenharia Agrícola e Ambiental, v.16, p.593-598, 2012.

Oliveira' M. V. A. M.; Villas-Bôas, R. L. Uniformidade de distribuição do potássio e do nitrogênio em sistema de irrigação por gotejamento. Engenharia Agrícola, v.28, p.95-103, 2008.

Prado, R. M. Nutrição de plantas. São Paulo: UNESP, 2008, $407 \mathrm{p}$.

Severino, L. S.; Ferreira, G. B.; Moraes, C. R. A.; Gondim, T. M. S.; Freire, W. S. A.; Castro, D. A.; Cardoso, G. D.; Beltrão, N. E.M Crescimento e produtividade da mamoneira adubada com macronutrientes e micronutrientes. Pesquisa Agropecuária Brasileira, v.41, p. 563-568, 2006.

Souza, L. C. Respostas do amendoim à calagem e adubação mineral. UFC, 2007. 97p. Tese Doutorado

Tasso Júnior, L. C.; Marques, M. O.; Nogueira, G. A. L. A cultura do amendoim. Jaboticabal: UNESP, 2004. 218p.

Teixeira, L. A. J.; Natale, W.; Martins, A. L. M. Nitrogênio e potássio em bananeira via fertirrigação e adubação convencional-atributos químicos do solo. Revista Brasileira de Fruticultura, v.29, p.143-152, 2007.

Uchôa, S. C. P.; Ivanof, M. E. A.; Alves, J. M. A.; Sediyama, T.; Martins, S. A. Adubação de potássio em cobertura nos componentes de produção de cultivares de girassol. Revista Ciência Agronômica, v.42, p.8-15, 2011. 